\title{
Psychometric properties of the Korean version of the Pulmonary Rehabilitation Adapted Index of Self-Efficacy (PRAISE) for individuals with COPD
}

This article was published in the following Dove Press journal:

International Journal of COPD

29 August 2017

Number of times this article has been viewed

\author{
Hee-Young Song' \\ Kyoung A Nam² \\ 'Department of Nursing, Wonju \\ College of Medicine, Yonsei University, \\ Wonju, South Korea; ${ }^{2}$ Division \\ of Nursing, Hallym University, \\ Chuncheon, South Korea
}

Purpose: Self-efficacy is related to the emotional functioning and coping skills of an individual and is thought to be a predictor of health behaviors, which are particularly important for pulmonary rehabilitation (PR). To our knowledge, no measure of self-efficacy has been validated to explore behavior changes in the context of PR for patients with COPD in Korea. This study aimed to evaluate the psychometric properties of the Korean version of the Pulmonary Rehabilitation Adapted Index of Self-Efficacy (PRAISE).

Patients and methods: The original scale, developed and validated by Vincent et al was translated into Korean through a process involving forward and back translation of the original scale, and transcultural adaptation was performed following the structured procedure. Content validity was assessed by a panel of 6 expert judges. In a convenience sample of 118 patients with COPD, exploratory factor analysis using principal axis factoring, followed by oblique rotation was conducted to identify construct validity, and the concurrent validity was evaluated by testing correlations between the PRAISE and 6-minute walking distance test and the PRAISE and Saint George Respiratory Questionnaire results. Internal consistency was examined by calculating Cronbach's alpha coefficients.

Results: Exploratory factor analysis confirmed the 2-dimensional structure of the scale constructed from the original 15-item scale. The final scale was composed of 14 items that cumulatively explained $60.3 \%$ of the total variance. The 2 factors in the scale were named "general self-efficacy" and "exercise self-efficacy." Significant correlations between the PRAISE, and 6-minute walking distance test and Saint George Respiratory Questionnaire showed the concurrent validity of the PRAISE. The Cronbach's alpha coefficient of the PRAISE was 0.93 .

Conclusion: The Korean version of the PRAISE showed adequate construct validity and reliability. These results suggest that the PRAISE is suitable for use in clinical settings as a predictor of PR behavior in Korean patients with COPD.

Keywords: COPD, self-efficacy, PRAISE, validity, reliability

\section{Introduction}

Individuals with COPD are expected to show progressive decrease in their functional status and eventually in their health-related quality of life, ${ }^{1,2}$ imposing an enormous burden on patients, health care professionals, and society at large. ${ }^{3}$ COPD is listed to be among the top 3 leading causes of death worldwide in $2030 .^{4}$ In Korea, COPD is currently ranked seventh among the causes of death. ${ }^{5}$ Moreover, the prevalence of COPD in adults aged 65 years and older was $31.0 \%$, which was 2 times higher than that in adults $<65$ years old $(14.2 \%)$, in $2016 .{ }^{5}$ Considering the very rapid aging of 
the Korean population, the higher prevalence of COPD in the older population in Korea is likely to increase the prevalence of COPD in the near future, which will increase the burden on the Korean national health care system.

To reduce this expected burden and to improve the quality of life for individuals with COPD, self-management of COPD has been highlighted as a potential approach. ${ }^{6,7}$ This approach has yielded clear effects. ${ }^{8}$ Self-management strategies rely on an individual's ability to manage symptoms, treatment, physical and psychosocial consequences, and lifestyle changes inherent in living with a chronic disease. ${ }^{9}$ Effective self-management can include patient education, support for decision-making, self-monitoring, and psychological and social support. ${ }^{8}$ Among the various forms of self-management interventions, those developed with self-efficacy (SE) as the underpinning theoretical framework have shown the most promise. ${ }^{10}$ Studies on the effectiveness of self-management interventions focusing on SE enhancement have suggested that they could improve overall health status ${ }^{7,11}$ or health behaviors $^{12}$ in individuals with COPD.

SE is a psychological construct defined as an individual's beliefs about their capabilities to control events that affect their lives ${ }^{13}$ and is recognized as one of the most important determinants in the adoption and maintenance of behavior changes. ${ }^{7,14}$ Since SE has emerged as an important correlate with health behavior, ${ }^{15}$ accurate measurement of SE is critical for evaluating the success of disease management.

Previous studies measuring SE within the rehabilitation forum have used well-validated tools that measure SE in a variety of ways. ${ }^{16}$ For example, the COPD SE scale (CSES) developed by Wigal et $\mathrm{al}^{17}$ measures the self-confidence levels in people with COPD regarding their ability to manage breathing difficulties and perform activities of daily life. This scale was translated into and validated in Norwegian, Danish, Korean, and Chinese ${ }^{16}$ and is the most studied instrument for assessing SE among patients with COPD. While the CSES measures SE comprehensively rather than the perceived capability for specific activities, some tools measured a domain-specific component of SE, such as SE for exercise. ${ }^{12}$

Any of the above-mentioned tools are useful for assessing COPD patients, as they are specific for the population with COPD and the challenges associated with this disease, and SE can be measured using general or activity/domain-specific scales. ${ }^{12}$ For example, while Bandura ${ }^{18}$ recommended that SE be measured as the perceived capability for specific activities, others maintained that measuring general self-efficacy (GSE) has utility for explaining behavior across task and less specific contexts. ${ }^{19,20}$ Along with general self-efficacy, measuring specific SE can help researchers and practitioners identify domains/activities that need to be addressed for improving patients' health, tailoring interventions to patients' needs, and measuring effectiveness of the interventions by measuring behavioral changes among individuals with COPD. ${ }^{12}$

The Pulmonary Rehabilitation Adapted Index of SE (PRAISE) developed by Vincent et $\mathrm{al}^{21}$ is composed of 10 items from the GSE scale of Schwarzer and Jerusalem, ${ }^{20}$ and 5 items for task-specific SE related to a pulmonary rehabilitation (PR) program. It has shown sensitivity to change, enabling documentation of improvement in a patient's level of SE after completing a PR program. ${ }^{22-24}$

Since SE has emerged as an important correlate of health behavior, ${ }^{15}$ improvement in SE as measured by the PRAISE might predict the translation of benefits from PR programs into tangible functional improvements in activities of daily living. Within this context, we propose that a sensitive instrument that is practical and useful in clinical settings is needed to measure perceived capability and belief on challenges and behaviors specific to the context of COPD.

To our knowledge, there are no studies to validate the PRAISE tool in Korean. This study aimed to translate the PRAISE into Korean, perform transcultural adaptation, and to investigate the psychometric properties of the Korean version of the PRAISE in Korean individuals with COPD.

\section{Materials and methods Study design}

This was a cross-sectional study consisting of translation of the original PRAISE tool into Korean and transcultural adaptation, followed by an evaluation of the psychometric properties of the Korean version of the PRAISE.

\section{Translation and transcultural adaptation process}

The translation and transcultural adaptation process was performed according to well-accepted international guidelines. ${ }^{25,26}$ First, permission to translate and use PRAISE was obtained from the corresponding author of the paper describing the original version. ${ }^{21}$

The original PRAISE was translated into Korean through a standard forward-backward translation procedure, ${ }^{25}$ transcultural adaptation was performed following the structured procedure described by Beaton et al. ${ }^{26}$ The first translation was performed independently from English to Korean by 3 bilingual translators who had majored in nursing, had lived 
in an English-speaking country for $>10$ years, and had $>3$ years of clinical experience. Next, a bilingual nursing professor reviewed the first version of the Korean translation and determined if it was relevant to Korean situations, both semantically and culturally. Minor revisions, such as changes in verbs, adjectives, or adverbs, were performed in this step. Then, the Korean translation was independently translated back to English by 2 other bilingual translators who had lived in an English-speaking country for over 10 years and had majored in nursing. The back-translated version was then reviewed by the original author and all questions were determined to well reflect the original version. Finally, a committee consisting of 4 health care professionals experienced in caring for patients with COPD compared the back-translated version reviewed by the original author to the original. Most of the translated questions were determined to be similar to the original questions, with a few minor changes in wording recommended by the committee.

\section{Psychometric test of the Korean version of the PRAISE}

\section{Participant recruitment and sample collection}

Eligible participants were consecutively recruited from individuals with COPD who had been treated at an outpatient department of pulmonology at an academic medical center in Wonju City, South Korea, between November 2016 and April 2017. In this study, the sample size of 118 met the criterion that the study sample size should be $>100 .{ }^{27}$ This criterion was based on several guiding rules of thumb cited in the literature, although a clear consensus could not be reached regarding required sample size in factor analysis. ${ }^{28}$ All participants met the following inclusion criteria: at least 45 years of age with physician-diagnosed COPD, spirometry forced expiratory volume in $1 \mathrm{~second} /$ forced vital capacity ( $\mathrm{FEV}_{1} / \mathrm{FVC}$ ) results $<70 \%$ and $\mathrm{FEV}_{1}<70 \%$, and capable of independent mobility. The study excluded patients with: 1) history of other lung diseases, including pneumoconiosis, bronchiectasis, pulmonary tuberculosis, primary pulmonary hypertension, pulmonary embolism, and interstitial lung disease; 2) any concomitant diseases that could interfere with the patient's general condition such as diabetes, renal failure, cancer, and mental disease; and 3) neuromuscular impairment that would interfere with the patient's mobility.

All participants answered a structured questionnaire on the study variables and completed a 6-minute walking distance (6-MWD) test. All surveys and tests were conducted by 2 research assistants, each of whom had completed a 6-hour training session, to ensure their consistency.

\section{Measurements Demographics and disease-related characteristics}

A structured questionnaire was used to collect information on participant demographic characteristics such as age, sex, education, marital status, economic status, and occupation. Information on disease-related characteristics was obtained using a modified Medical Research Council (mMRC) dyspnea scale and a question on self-reported smoking history. The mMRC is a 5-point scale that assesses the degree of breathlessness on a scale from 0 (not troubled by breathlessness except with strenuous exercise) to 4 (too breathless to leave the house or breathless when dressing or undressing). ${ }^{7,29}$ Medical records were reviewed to assess cardiovascular comorbidities, disease duration, and spirometry results for the pulmonary function test (PFT). The FEV ${ }_{1}, \mathrm{FVC}$, and $\mathrm{FEV}_{1} /$ FVC ratio were obtained from spirometry PFT results of tests performed within the past 3 months. ${ }^{30} \mathrm{FEV}_{1}$ values were used to classify COPD by severity according to lung function impairment using the following cut-offs: stage I/mild $\mathrm{COPD}, \mathrm{FEV}_{1} \geq 80 \%$ predicted; stage $\mathrm{II} /$ moderate COPD, $50 \% \leq \mathrm{FEV}_{1}<80 \%$ predicted; stage III/severe COPD, $30 \% \leq \mathrm{FEV}_{1}<50 \%$ predicted; and stage IV/very severe $\mathrm{COPD}, \mathrm{FEV}_{1}<30 \%$ predicted. ${ }^{31}$ The breakdown of disease severity among participants is presented in Table 1 .

\section{The original PRAISE tool}

The original PRAISE tool is an adapted version of the GSE scale (GSES) ${ }^{20}$ that was developed and validated specifically for use in PR and has been fully validated in a PR population ${ }^{21}$ in the UK. The original GSES is a 10-item scale measuring generalized perceived SE at any given time. ${ }^{20}$

Typical items are "Thanks to my resourcefulness, I know how to handle unforeseen situation" and "When I am confronted with a problem, I can usually find several solutions." However, the GSES is a general measure that does not address specific behaviors around lifestyle changes. Therefore, as the original authors of the GSES suggested adding statements to measure changes in specific $\mathrm{SE},{ }^{20}$ 5 additional items addressing the specific challenges faced by individuals with COPD were added to the PRAISE tool; ${ }^{21}$ these items included assessing how able they felt to cope with exercise and how informed they felt about their disease. Example items are "I feel confident that I will be able to perform the exercises asked for me during the course of rehabilitation, even if I find them difficult". The items were generated by expert clinicians in focus groups, and were confirmed by patients and health psychologists. The PRAISE 
Table I Participant characteristics $\mathrm{N}=$ I | 8

\begin{tabular}{|c|c|c|c|}
\hline Variable & Category & n (\%) & Mean \pm SD \\
\hline General & Age (years) & & $69.41 \pm 9.23$ \\
\hline \multirow[t]{21}{*}{ characteristics } & $<65$ & $34(28.8)$ & \\
\hline & $65-75$ & $48(40.7)$ & \\
\hline & $>75$ & $36(30.5)$ & \\
\hline & Sex & & \\
\hline & Male & $103(87.3)$ & \\
\hline & Female & $15(12.7)$ & \\
\hline & Education & & \\
\hline & $\leq$ Middle school & $67(56.8)$ & \\
\hline & $\leq$ High school & $34(28.8)$ & \\
\hline & $\geq$ College & $17(14.4)$ & \\
\hline & Marital status & & \\
\hline & Married & 115 (97.4) & \\
\hline & Single & $3(2.6)$ & \\
\hline & Economic status & & \\
\hline & Low & $3(2.6)$ & \\
\hline & Middle & $70(59.3)$ & \\
\hline & High & $45(38.1)$ & \\
\hline & Occupation & & \\
\hline & None & $66(55.9)$ & \\
\hline & Self-employed & $44(37.3)$ & \\
\hline & Office worker & $8(6.8)$ & \\
\hline Disease-related & Duration of disease (years) & & $10.05 \pm 9.07$ \\
\hline \multirow[t]{30}{*}{ characteristics } & $<10$ & $77(65.3)$ & \\
\hline & $11-19.9$ & $20(16.9)$ & \\
\hline & $\geq 20$ & $21(17.8)$ & \\
\hline & Cardiovascular comorbidit & ies & \\
\hline & Hypertension & $15(12.7)$ & \\
\hline & Heart problems & $18(15.3)$ & \\
\hline & None & $85(72.0)$ & \\
\hline & Smoking & & \\
\hline & Never & $22(18.7)$ & \\
\hline & Ex-smoker & $83(70.3)$ & \\
\hline & Current smoker & $13(\mid 1.0)$ & \\
\hline & mMRC dyspnea & & \\
\hline & 0 & II (9.3) & \\
\hline & $\mathrm{I}$ & $49(4 \mid .5)$ & \\
\hline & 2 & $24(20.4)$ & \\
\hline & 3 & $17(14.4)$ & \\
\hline & 4 & $17(14.4)$ & \\
\hline & Body mass index $\left(\mathrm{kg} / \mathrm{m}^{2}\right)$ & & $22.87 \pm 3.72$ \\
\hline & $<19$ & $13(\mid 1.0)$ & \\
\hline & $19-22.9$ & $5 \mathrm{I}(43.2)$ & \\
\hline & $23-24.9$ & $28(23.7)$ & \\
\hline & $\geq 25$ & $26(22.1)$ & \\
\hline & Airflow obstruction & & \\
\hline & $\mathrm{FEV}_{1}$ & & $63.51 \pm 24.01$ \\
\hline & $\mathrm{FEV}_{1} / \mathrm{FVC}$ & & $54.47 \pm 19.61$ \\
\hline & GOLD stage & & \\
\hline & I & $32(27.1)$ & \\
\hline & II & $49(4 \mid .5)$ & \\
\hline & III & $27(22.9)$ & \\
\hline & IV & $10(8.5)$ & \\
\hline
\end{tabular}

Abbreviations: FEV, forced expiratory volume; FVC, forced vital capacity; GOLD, Global initiative for chronic Obstructive Lung Disease; mMRC, modified Medical Research Council. consisted of 15 questions, each of which was scored on a scale from 1 to 4 , with a score range of 15 to 60 , and a higher score indicated a higher level of perceived SE.

\section{Validating instruments}

The following measurements were used to test the validity of the Korean version of the PRAISE.

The 6-MWD test: The 6-MWD test was conducted following standardized instructions. ${ }^{30}$ Briefly, the mean distances (in meters) of the best 2 of 3 self-paced 6-minute hallway walks were recorded. During the 6-MWD test, patients were encouraged to walk at their own pace and rest as needed in order to control breathlessness. Chairs were provided along the hallway in the event that patients needed to rest during the walk. The 6-MWD test is a well-established test to assess patients' functional status and has been shown to be the strongest indication of patient response to clinical intervention in PR..$^{30}$

Saint George Respiratory Questionnaire (SGRQ): The validated Korean version of the $\mathrm{SGRQ}^{32}$ was used. This assessment is a self-administered, disease-specific questionnaire that includes 50 items representing 3 content areas that are of particular importance to COPD, symptoms, activities, impacts, as well as their total. ${ }^{33,34}$ The scores range from 100 (worst possible health status) to 0 (best possible health status). In the current study, the Cronbach's alpha values for the symptoms, activity, impact, and total subscales were $0.95,0.88,0.89$, and 0.94 , respectively.

\section{Data analysis}

The subjects' clinical and sociodemographic characteristics were described using mean values and standard deviations or counts and percentages. The data were analyzed using IBM SPSS version 23 (IBM Corp, Armonk, NY, USA) and specific analyses for each property are described below. Significance level $\alpha$ was set at 0.05 for the 2-tailed tests of statistics, and a $p$-value $<0.05$ was considered significant.

\section{Content validity}

Content validity was assessed on the pre-final version of the questionnaire by a panel of 6 expert judges. The panel included 2 doctoral students and 2 nursing professors experienced in instrument translation and implementation research, in addition to a head nurse and a pulmonologist who had cared for patients with COPD for $>10$ years. Members of the panel of experts were asked to conduct a qualitative evaluation of every item (degree of understanding, agreement 
with the text) and also a quantitative assessment of each item according to the following criteria: 1) competence (items belonging to theoretical established factors); 2) clarity (item was easily understood; its semantics and syntactics were suitable); 3) coherence (item had a relation with the factor being measured), and 4) relevance (item was essential and had to be included). The item content validity index (I-CVI) score was calculated with a Likert-type 4-point scale by the panel of 6 experts to quantify the content validity. The scalecontent validity index/average (S-CVI/Ave) was calculated by summing the I-CVIs and dividing by the number of items. Further, 18 patients with COPD were invited to evaluate the tool for ease of use and item clarity.

\section{Construct validity}

Exploratory factor analysis (EFA) using principal axis factoring (PAF) was conducted to verify the simple factor structure of the PRAISE. In the first step of the EFA, to assess the suitability of respondent data for factor analysis, we evaluated correlation matrix, test of Kaiser-Meyer-Olkin (KMO) measures of sampling adequacy, and Bartlett's test of sphericity. In the second step of EFA, to extract the initial factor solution, we used PAF, which is one of the common factor extraction methods producing accurate solutions by estimating the common or shared variance. ${ }^{35} \mathrm{We}$ determined the number of factors in order to apply multiple criteria, such as the eigenvalue of each factor, scree plot, and the cumulative percent of variance explained by the factors. In the final step of the EFA, factor rotation was conducted to improve factor interpretation by maximizing high item loadings and minimizing low item loadings. ${ }^{28}$ As some correlations among factors were expected, we chose an oblique oblimin factor rotation method. After rotation, items that had factor loadings over 0.45 were retained. ${ }^{36}$ After a parsimonious factor structure was derived from the EFA, the factors were labeled based on the item content.

\section{Concurrent validity}

The concurrent validity was assessed by hypotheses testing using the correlations between the observed test scores of the questionnaires of the PRAISE tool, SGRQ, and 6-MWD. We hypothesized that the concurrent validity of the PRAISE would be verified if there were significant correlations between the PRAISE and 6-MWD and between the PRAISE and SGRQ results. Pearson's correlation coefficient was used to examine concurrent validity with the 2-tailed test.

\section{Reliability}

The internal reliability of the Korean version of the PRAISE was assessed by calculating Cronbach's alpha and inter-items correlations.

\section{Ethical considerations}

The research protocol was approved by the Institutional Review Board of Wonju College of Medicine, Yonsei University (YWNR-14-9-103). Patients who met the inclusion criteria were invited to participate in the study. Those who agreed to participate provided written informed consent after the principal investigator explained the purpose of the study, provided assurance of privacy, explained potential benefits and risks, and communicated the voluntary nature of their participation and the possibility for withdrawal without penalty.

\section{Results Characteristics of the participants}

A total of 118 patients were included in the final analysis. Out of the entire study population, $87.3 \%$ were male, and the mean age was 69.41 years old. The average disease duration was 10.05 years, $72 \%$ of participants reported no concurrent cardiovascular disease, and $89.0 \%$ of participants claimed to be current non-smokers.

Among participants, $41.5 \%$ were classified as mMRC dyspnea scale grade 1, meaning that they got short of breath when hurrying on level ground or walking up a slight hill, 9.3\% reported no breathlessness except with strenuous exercise (grade 0), and 14.4\% reported that they were too breathless to leave the house or became breathless when dressing or undressing (grade 4). The mean $\mathrm{FEV}_{1}$ and $\mathrm{FEV}_{1} /$ FVC ratio were $63.5 \%$ and $54.5 \%$, respectively. Regarding severity of airflow obstruction as assessed by Global initiative for chronic Obstructive Lung Disease (GOLD) stage, most of the patients had stage II obstruction (41.5\%), followed by stage I (27.1\%) and stage III (22.9\%) (Table 1).

\section{Content validity}

The PRAISE tool had acceptable content validity because a considerable number of experts judged the questions to be relevant for SE. The I-CVI values ranged from 0.8 to 1.0 , and $\mathrm{S}-\mathrm{CVI} /$ Ave was determined to be 0.96 (Table 2). Given that it must comprise items with an I-CVI of 0.78 or higher and an S-CVI of 0.90 or higher to be judged as having excellent content validity, ${ }^{37}$ the content validity of the Korean version of the PRAISE tool was determined to be acceptable. 
Table 2 Reliability and factor loadings for the PRAISE



Abbreviations: I-CVI, item content validity index; PRAISE, pulmonary rehabilitation adapted index of self-efficacy.

Also, 18 patients with COPD who had been invited to evaluate the tool reported no difficulty while completing the PRAISE, and that the meaning of the 15 items could be clearly understood.

\section{Construct validity}

Before the factorization of a set of variables, the possibility of factor analysis has to be demonstrated using correlation among variables. A KMO statistic of 0.918 and the individual KMOs were $0.810-0.970$ over the criterion of $0.6,{ }^{38}$ indicating sampling adequacy. Moreover, Bartlett's test of sphericity reached statistical significance $\left(\chi^{2}=1,277.46, p=0.000\right)$.

We conducted EFA using PAF to extract initial factor solution and determined the number of factors to retain with various criteria. Two factors were determined by an eigenvalue larger than 1 . The scree plot also indicated 2 factors, and the cumulative percent of variance explained by the 2 factors was $58.3 \%$. These results demonstrated that a 2-factor solution was appropriate for the simple structure of our data.

The result of the direct oblimin factor rotation with the original 15 items in the 2-factor solution indicated that 1 item (item number 1) did not fit well statistically, as evidenced by a low factor loading under $0.45^{36}$ and cross-loading (factor 1 : 0.290, factor 2: 0.307 ) on both factors. After deleting this item, factor analysis was conducted with 14 items. The results showed that the 2-factor solution explained a total of $60.3 \%$ of the variance, with $53.8 \%$ contributed by factor 1 and $6.5 \%$ contributed by factor 2 (Table 2).

The correlation coefficient between factors 1 and 2 was significant $(r=0.62)$ (Table 3$)$.

Items loaded on factor 1 mostly measured SE in general; for example, "When I am confronted with a problem, I can usually find several solutions." On the other hand, the 3 items loaded on factor 2 were more likely to measure self-confidence in physical activity, such as "I feel confident that I will be able to perform the exercises asked of me during the course of rehabilitation, even if I find them difficult." Based on the content of the retained items of the 2 factors, the first factor was labeled as "General Self-efficacy" (GSE) and the second factor as "Exercise Self-efficacy" (ESE).

Table 3 Correlations between the PRAISE factors

\begin{tabular}{lll}
\hline & Factor I & Factor 2 \\
\hline Factor I & $\mathrm{I}$ & \\
Factor 2 & $0.62^{* *}$ & $\mathrm{I}$ \\
PRAISE total score & $0.97^{* *}$ & $0.78^{* *}$ \\
\hline
\end{tabular}

Note: **Correlation is significant at the 0.01 level.

Abbreviation: PRAISE, pulmonary rehabilitation adapted index of self-efficacy. 
Table 4 Correlations between the PRAISE, 6-MWD, and SGRQ scores

\begin{tabular}{clllll}
\hline Variable & 6-MWD & \multicolumn{2}{l}{ SGRQ } & & \\
\cline { 3 - 6 } & & Total & Symptom & Activity & Impact \\
\hline Total SE & & & & & \\
$r$ & $0.214^{*}$ & $-0.345^{* *}$ & $-0.32 I^{* *}$ & $-0.300^{* *}$ & $-0.314^{* *}$ \\
$\quad p$ & 0.039 & 0.000 & 0.000 & 0.001 & 0.001 \\
General SE & & & & & \\
$r$ & 0.157 & $-0.302^{* *}$ & $-0.329 * *$ & $-0.228^{*}$ & $-0.285^{* *}$ \\
$p$ & 0.132 & 0.001 & 0.000 & 0.013 & 0.002 \\
Exercise SE & & & & & \\
$r$ & $0.308^{* *}$ & $-0.353^{* *}$ & $-0.205^{*}$ & $-0.399^{* *}$ & $-0.295^{* *}$ \\
$p$ & 0.003 & 0.000 & 0.026 & 0.000 & 0.001 \\
\hline
\end{tabular}

Notes: $*$ Correlation is significant at the 0.05 level. **Correlation is significant at the 0.01 level.

Abbreviations: PRAISE, pulmonary rehabilitation adapted index of self-efficacy; 6-MWD, 6-minute walking distance; SE, self-efficacy; SGRQ, Saint George Respiratory Questionnaire.

\section{Concurrent validity}

The score of the PRAISE positively correlated with that of the 6-MWD $(r=0.214, p=0.039)$ and negatively correlated with that of the SGRQ $(r=-0.345, p=0.000)$, which indicated the concurrent validity of the PRAISE tool. Specifically, the first factor of PRAISE (GSE) was not significantly correlated with the 6-MWD $(r=0.157, p=0.132)$, while it was negatively correlated with the SGRQ $(r=-0.302, p=0.001)$. The second factor of PRAISE (ESE) was significantly correlated with both the 6-MWD $(r=0.308, p=0.003)$ and SGRQ $(r=-0.353, p=0.000)$ (Table 4).

\section{Reliability}

The standardized Cronbach's alpha coefficient for the final 14 items was 0.93 . The coefficient for the first factor was 0.94 , and the coefficient for the second factor was 0.79 , suggesting acceptable reliability of the PRAISE (Table 2).

\section{Discussion}

The present study generated a Korean version of the PRAISE tool and explored the psychometric properties of the scale specifically for use in PR of patients with COPD. The results suggest that the PRAISE is a reliable tool that can be useful for detecting and predicting behavioral changes among this population.

In this study, $87.3 \%$ of the participants were male, and the mean age was 69 years, which is consistent with a recent report indicating that COPD was 3 times more prevalent in men $(20.6 \%)$ than in women $(6.8 \%)$ in Korea in $2013 .{ }^{5}$ Therefore, the participants in this study were representative of the population of patients with COPD in Korea. However, this result is not consistent with the ratios of men to women with
COPD that have been reported in other studies worldwide, in which the percentage of male patients ranged from $50 \%{ }^{12}$ to $55 \%{ }^{21}$ among the study participants.

During the cross-cultural adaptation of the PRAISE tool into Korean, no major difficulties were encountered during the back and forth translation processes. The expert committee review helped the tool achieve further semantic, idiomatic, and conceptual equivalence. The test of the prefinal version confirmed that a reasonable translation was reached because comprehension and equivalence issues were avoided. Also, the results of the face validity assessment highlighted the representation of problems specific to patients with COPD in the questionnaire.

The reliability estimate for the Korean version of the PRAISE tool in the current study was 0.93 . This finding is similar to the estimate obtained for the original version of the scale, $0.95 .{ }^{21}$ With the exception of item 1 , which was removed from the final version of the current study, the change in Cronbach's alpha if any item was deleted did not exceed the Cronbach's alpha for the whole scale, indicating that all 14 items were pertinent and necessary.

Item 1, which was removed, was "I can always manage to solve difficult problems if I try hard enough." This item assessed GSE in the original scale. This item had relatively low values on the I-CVI, corrected item to total correlation, and factor loading compared with the other items. One explanation for this result is that the content of this item is likely to be unfamiliar to participants in the current study, who were old and tended to avoid using decisive words such as "can always". However, this explanation is confined only to this study. Further studies with larger COPD populations with diverse characteristics are warranted to validate this explanation.

In this study, the EFA results revealed a 2-factor structure, showing that 11 items were loaded on factor 1 and the other 3 items on factor 2. In the original PRAISE tool, Vincent et $\mathrm{al}^{21}$ adapted 10 items from the GSES of Schwarzer and Jerusalem $^{20}$ and added 5 items for task-specific SE. This addition of items to the original scale might have increased the possibility for 2 different unidimensional reflective subscales to deal with multiple aspects of participant SE. Indeed, among the 5 items added by Vincent et $\mathrm{al}^{21} 2$ (item 9, item 15) were loaded on factor 1 along with the 10 items adapted from Schwarzer and Jerusalem's scale. ${ }^{20}$ The other 3 items (items 4, 7, and 12) were loaded on factor 2. However, as the original authors of the PRAISE tool did not suggest any factor structure, we cannot conclude if we found a different factor structure from that of the original. Therefore, the 
results of the current study should be interpreted with caution and further investigation into the measurement properties of the PRAISE tool is needed.

Another notable aspect of this 2-factor loading is that the Korean version of the PRAISE, which measures SE in general and $\mathrm{SE}$ in exercise, might give clearer information on what the scores of the PRAISE actually measure. DePew and $\mathrm{BenzO}^{39}$ had raised a question of scoring of the original PRAISE tool, which is an aggregate of GSE and PR-specific SE. This aggregation of subdomains into a single score could be misleading, because combining individual scores might result in unintended loss of details contained in specific domain scores, which, in turn, can bias result measures. ${ }^{39}$ From this perspective, the Korean version of the PRAISE tool, which is composed of 2 factors, is more likely to specify what the scores actually inform on SE among individuals with COPD. In particular, measuring ESE is critical in this population, regarding a convincing body of evidence on the effects of physical activity on COPD exacerbation and mortality, in addition to international recommendations emphasizing physical activity in COPD management. ${ }^{40,41}$ Therefore, the PRAISE tool by verifying ESE in individuals with COPD is useful for tailoring management according to the individual's needs and also for measuring the effects of management strategies.

The concurrent validity of the Korean version of the PRAISE in this sample was verified because its results showed significant correlations with those of the 6-MWD and SGRQ. Specifically, the GSE results were correlated only with the SGRQ results, while the ESE results were significantly correlated with the 6-MWD and SGRQ results. This finding is consistent with studies that have shown that GSE results are correlated with psychologic aspects and perceptions, such as anxiety, depression, and perceived health status, ${ }^{42}$ whereas they are not correlated with exercise capacity in patients with COPD. ${ }^{11}$ This result is notable because the Korean version of the PRAISE validated in the current study is useful for predicting both behavioral changes and psychologic variables underlying specific tasks in individuals with COPD.

Compared with the previously developed SE scale for COPD, the validated PRAISE in this study is more parsimonious and practical because it includes fewer items (14 items) and contains both general and specific SE domains, as well. For example, the 34-item CSES developed by Wigal et $\mathrm{al}^{17}$ is widely used in clinical studies of $\mathrm{COPD}^{11}$ to identify situations in which individuals afflicted with COPD experience low SE. However, Bentsen et al suggested that the large number of items or the content of the items in the CSES might lead to an incomplete reply from the respondents, and it was likely to limit the ability of this scale to capture SE. Therefore, the PRAISE validated in this study may be a tool to complement this limitation.

The results of the current study should be considered in light of several limitations. First, the cross-sectional design precludes causal inferences between SE and the health indicators assessed in this study. Moreover, the generalizability of the results might be limited because all study participants were enrolled in an outpatient department of a university hospital. Also, the participants were predominantly male, had a mean age of 69 years, and were classified as GOLD stage I $(27.1 \%)$ or II $(41.5 \%)$, even though the recruitment strategy was designed to enroll a representative sample of patients and limit selection bias.

Finally, the PRAISE tool uses a 4-point Likert scale and was treated as a continuous variable in the current study. Given that Likert scale data have been treated as a continuous variable by calculating a composite score (sum or mean) from items ${ }^{43,44}$ and the Likert scale is widely used in social science research, ${ }^{45}$ the scores calculating a sum of items of the PRAISE tool can be treated as continuous variables. However, the controversy on the reasonable number of response options of the Likert scale remains, leaving room for questions regarding statistical analysis and strategies to reduce this controversy. ${ }^{45}$ Therefore, the results of the current study should be also interpreted within the context of this controversy.

Further studies are warranted to explore whether the Korean version of the PRAISE can predict actual behavioral changes longitudinally and to refine the scale with a larger number of participants, including more women and more individuals with COPD who reside in the community. Also, studies should be conducted to verify if the items removed of those that were loaded low in the factor analysis in the current study apply only to the Korean population or to other international populations as well.

\section{Conclusion}

A Korean version of the PRAISE was validated in this study and showed sufficient reliability and validity to correspond well to the original version. The analyses showed a relationship between the underlying construct and relevant disease-specific variables (6-MWD and SGRQ), thereby indicating the validity of the tool. The Korean version of the PRAISE validated in the current study is a useful instrument for obtaining detailed information on an individual's 
beliefs related to a specific task and for predicting behavioral changes in individuals with COPD. Further studies should be conducted to refine the factor structure and to verify the utility and predictability of the instrument with a larger and more diverse sample of patients with COPD.

\section{Acknowledgment}

This research was supported by the Basic Science Research Program through the National Research Foundation of Korea (NRF) funded by the Ministry of Education (NRF2016R1D1A1A09918871).

\section{Author contributions}

The first author, HYS, conceived, planned, and executed the study, as well as wrote and revised the manuscript. The corresponding author, KAN, contributed to the study design, data analyses and interpretation, and manuscript writing and revision.

Both authors have read and approved the manuscript.

\section{Disclosure}

The authors report no conflicts of interest in this work.

\section{References}

1. Burtin C, Decramer M, Gosselink R, Janssens W, Troosters T. Rehabilitation and acute exacerbations. Eur Respir J. 2011;38(3):702-712.

2. Lomundal BK, Steinsbekk A. Five-year follow-up of a one-year selfmanagement program for patients with COPD. Int $J$ Chron Obstruct Pulmon Dis. 2012;7:87-93.

3. Zhang C, Wang W, Li J, et al. Development and validation of a COPD self-management scale. Respir Care. 2013;58(11):1931-1936.

4. World Health Organization. Process of translation and adaptation of instruments. [Homepage on the Internet]. 2005. Available from: http:/ www.who.int/substance_abuse/research_tools/translation/en/. Accessed Mar 15, 2017.

5. Korean Center for Disease Control \& Prevention. [2016 Chronic diseases current status and issues: chronic diseases factbook]. 2016 Current States and Issues in Chronic Ilness: Chronic illness Factbook. [homepage on the Internet]. 2016. Available from: http://www.guideline.or.kr/ newsletter/vol1609/file/201609_01.pdf. Accessed Mar 15, 2017.

6. Cannon D, Buys N, Sriram KB, Sharma S, Morris N, Sun J. The effects of chronic obstructive pulmonary disease self-management interventions on improvement of quality of life in COPD patients: A meta-analysis. Respir Med. 2016;121:81-90.

7. Selzler AM, Rodgers WM, Berry TR, Stickland MK. The importance of exercise self-efficacy for clinical outcomes in pulmonary rehabilitation. Rehabil Psychol. 2016;61(4):380-388.

8. Panagioti M, Richardson G, Small N, et al. Self-management support interventions to reduce health care utilisation without compromising outcomes: a systematic review and meta-analysis. BMC Health Serv Res. 2014;14:356

9. Barlow J, Wright C, Sheasby J, Turner A, Hainsworth J. Self-management approaches for people with chronic conditions: a review. Patient Educ Couns. 2002;48(2):177-187.

10. Abubakari AR, Cousins R, Thomas C, Sharma D, Naderali EK. Sociodemographic and clinical predictors of self-management among people with poorly controlled type 1 and type 2 diabetes: the role of illness perceptions and self-efficacy. J Diabetes Res. 2016;2016:6708164.
11. Bentsen SB, Wentzel-Larsen T, Henriksen AH, Rokne B, Wahl AK. Self-efficacy as a predictor of improvement in health status and overall quality of life in pulmonary rehabilitation an exploratory study. Patient Educ Couns. 2010;81(1):5-13.

12. Jackson BE, Coultas DB, Ashmore J, et al. Domain-specific self-efficacy is associated with measures of functional capacity and quality of life among patients with moderate to severe chronic obstructive pulmonary disease. Ann Am Thorac Soc. 2014;11(3):310-315.

13. Bandura A. Self-Efficacy: The Exercise of Self-Control. New York: Freeman; 1997.

14. Rice K, Bourbeau J, MacDonald R, Wilt TJ. Collaborative selfmanagement and behavioral change. Clin Chest Med. 2014;35(2): $337-351$.

15. Emme C, Mortensen EL, Rydahl-Hansen S, Ostergaard B, Phanareth K. Danish version of "The COPD self-efficacy scale": translation and psychometric properties. Scand J Caring Sci. 2012;26(3): 615-623.

16. Clari M, Matarese M, Alvaro R, Piredda M, De Marinis MG. Measurement properties of instruments evaluating self-care and related concepts in people with chronic obstructive pulmonary disease: a systematic review. Heart Lung. 2016;45(5):441-448.

17. Wigal JK, Creer TL, Kotses H. The COPD self-efficacy scale. Chest. 1991;99(5):1193-1196.

18. Bandura A. Guide for construction self-efficacy scales. In: Pajares F, Urdan T, eds. Self-Efficacy Beliefs of Adolescents. Vol 5. Greenwich, CT: Information Age Publishing; 2006:307-337.

19. Chen G, Gully SM, Eden D. Validation of a new general self-efficacy scale. Organ Res Methods. 2001;4(1):62-83.

20. Schwarzer R, Jerusalem M. Generalized self-efficacy scale. In: Weinman J, Wright S, Johnston M, eds. Measures in Health Psychology: A User's Portfolio. Causal and Control Beliefs. Windsor, UK: NFERNELSON; 1995:35-37.

21. Vincent E, Sewell L, Wagg K, Deacon S, Williams J, Singh S Measuring a change in self-efficacy following pulmonary rehabilitation: an evaluation of the PRAISE tool. Chest. 2011;140(6): 1534-1539.

22. Harrison SL, Robertson N, Graham CD, et al. Can we identify patients with different illness schema following an acute exacerbation of COPD a cluster analysis. Respir Med. 2014;108(2):319-328.

23. Holland AE, Mahal A, Hill CJ, et al. Home-based rehabilitation for COPD using minimal resources: a randomised, controlled equivalence trial. Thorax. 2017;72(1):57-65.

24. Mitchell KE, Johnson-Warrington V, Apps LD, et al. A self-management programme for COPD: a randomised controlled trial. Eur Respir J. 2014;44(6):1538-1547.

25. Behling O, Law KS. Translating Questionnaires and Other Research Instruments: Problems and Solutions. Thousand Oaks, CA: SAGE Publications; 2000.

26. Beaton DE, Bombardier C, Guillemin F, Ferraz MB. Guidelines for the process of cross-cultural adaptation of self-report measures. Spine (Phila Pa 1976). 2000;25(24):3186-3191.

27. Hair JF. Multivariate Data Analysis. 7th ed. Upper Saddle River, NJ: Prentice Hall; 2010.

28. Williams B, Onsman A, Brown T. Australian paramedic graduate attributes: a pilot study using exploratory factor analysis. Emerg Med $J$. 2010;27(10):794-799.

29. Nishimura K, Izumi T, Tsukino M, Oga T. Dyspnea is a better predictor of 5-year survival than airway obstruction in patients with COPD. Chest. 2002;121(5):1434-1440.

30. ATS Committee on Proficiency Standards for Clinical Pulmonary Function Laboratories. ATS statement: guidelines for the six-minute walk test. Am J Respir Crit Care Med. 2002;166(1):111-117.

31. Global Initiative for Chronic Obstructive Lung Disease. GOLD 2017 Global strategy for the diagnosis, management and prevention of COPD [Homepage on the Internet]. Available from: http://goldcopd.org/ gold-2017-global-strategy-diagnosis-management-prevention-copd/ Accessed Mar 15, 2017. 
32. Kim YS, Byun MK, Jung WY, et al. Validation of the Korean version of the St. George's respiratory questionnaire for patients with chronic respiratory disease. Tuberc Respir Dis. 2006;61(2):121-128.

33. Jones PW, Quirk FH, Baveystock CM, Littlejohns P. A self-complete measure of health status for chronic airflow limitation. The St. George's Respiratory Questionnaire. Am Rev Respir Dis. 1992;145(6): 1321-1327.

34. Wilson CB, Jones PW, O'Leary CJ, Cole PJ, Wilson R. Validation of the St. George's Respiratory Questionnaire in bronchiectasis. Am J Respir Crit Care Med. 1997;156(2 Pt 1):536-541.

35. Thompson B. Exploratory and Confirmatory Factor Analysis: Understanding Concepts and Applications. Washington, D.C.: American Psychological Association; 2004.

36. Comrey AL, Lee HB. Interpretation and application of factor analytic results. In: Comrey AL, Lee HB, eds. A First Course in Factor Analysis. 2nd ed. NY: Lawrence Erlbaum Associates, Inc; 1992.

37. Polit DF, Beck CT. The content validity index: are you sure you know what's being reported? Critique and recommendations. Res Nurs Health. 2006;29(5):489-497.
38. Kaiser HF. An index of factorial simplicity. Psychometrika. 1974;39(1): 31-36.

39. DePew ZS, Benzo R. What is the pulmonary rehabilitation adapted index of self-efficacy tool actually measuring? Chest. 2012;141(4): 1123-1124.

40. Gimeno-Santos E, Frei A, Steurer-Stey C; PROactive consortium, et al. Determinants and outcomes of physical activity in patients with COPD: a systematic review. Thorax. 2014;69(8):731-739.

41. Thorpe O, Kumar S, Johnston K. Barriers to and enablers of physical activity in patients with COPD following a hospital admission: a qualitative study. Int J Chron Obstruct Pulmon Dis. 2014;9:115-128.

42. Love J, Moore CD, Hensing G. Validation of the Swedish translation of the general self-efficacy scale. Qual Life Res. 2012;21(7): 1249-1253.

43. Boone HN, Boone DA. Analyzing likert data. J Ext. 2012;50(2):1-5.

44. Furr RM, Bacharach VR. Psychometrics. Thousand Oaks: Sage; 2014.

45. Wu H, Leung SO. Can likert scales be treated as interval scales? A simulation study. J Soc Serv Res. 2017:1-6.

\section{Publish your work in this journal}

The International Journal of COPD is an international, peer-reviewed journal of therapeutics and pharmacology focusing on concise rapid reporting of clinical studies and reviews in COPD. Special focus is given to the pathophysiological processes underlying the disease, intervention programs, patient focused education, and self management protocols.

\section{Dovepress}

This journal is indexed on PubMed Central, MedLine and CAS. The manuscript management system is completely online and includes a very quick and fair peer-review system, which is all easy to use. Visit $\mathrm{http}: / /$ www.dovepress.com/testimonials.php to read real quotes from published authors. 